\title{
Nasal Reconstruction Using Tissue Expander and Modified Paramedian Forehead Flap Supported by Cartilage Graft
}

\author{
Pauline Yap ${ }^{1}$ (D) Nurul Syazana Mohamad Shah ${ }^{2}$ (D), Arman Zaharil Mat Saad ${ }^{3}$ (1), \\ Wan Azman Wan Sulaiman² (D), Siti Fatimah Noor Mat Johar ${ }^{2}$ (D)
}

\author{
${ }^{1}$ Universiti Malaysia Sabah, Department of Surgery, Faculty of Medicine Health Sciences, Kota Kinabalu, Sabah, Malaysia \\ ${ }^{2}$ Universiti Sains Malaysia, Health Campus, School of Medical Sciences, , Reconstructive Sciences Unit, Kubang Kerian, Kelantan, Malaysia \\ ${ }^{3}$ Plastic and Reconstructive Unit, MSU Medical Centre, Management and Science University, Shah Alam, Selangor, Malaysia
}

ORCID ID: P.Y. 0000-0002-2228-3473; N.S.M.S. 0000-0001-6731-9962; A.Z.M.S. 0000-0002-4003-6783; W.A.W.S. 0000-0002-0600-9765;

S.F.N.M.J. 0000-0003-4120-4918

Citation: Yap P, Shah NSM, Saad AZM, Sulaiman WAW, Mat Johar SFN. Nasal reconstruction using tissue expander and modified paramedian forehead flap supported by cartilage graft. Tr-ENT 2021;31(2):51-8. https://doi.org/10.26650/Tr-ENT.2021.18480

\section{ABSTRACT}

This is an interesting case of a male patient with traumatic nasal injury with partial nasal amputation who was referred to our centre 3 months after the initial trauma. The wound was complicated with necrosis, the amputated nose had fallen off and a scar had formed at the wound bed. The nasal defect was greater than $2.5 \mathrm{~cm}$ in length. More than $50 \%$ of the nose had fallen off including the bilateral alar lobule, the tip and the dorsal part of the nose. We utilized a tissue expander to create more tissue on the forehead in view of the patient's short forehead, for donor site closure and to lengthen our flap. We performed a modified paramedian forehead flap with a widened distal portion of flap, in a two-staged nasal reconstruction surgery supported by L-strut cartilage graft harvested from the $7^{\text {th }}$ rib. In this report we provide an illustrative description of the procedure, its cosmetic and functional outcome and we also share the challenges we faced.

Keywords: Nasal reconstruction, traumatic nasal injury, rhinoplasty

\section{INTRODUCTION}

The human nose which is situated at the centre of the face in a prominent form makes it vulnerable to trauma and cutaneous malignancy. These conditions often result in a distorted facial appearance that requires nasal reconstruction. The aesthetic and functional results of a nasal reconstruction depends on a surgeon's ability to imagine the nasal structural defect in a three-dimensional figure. This is important for the proper assessment of the defect and subsequently reconstruct the nasal deformit. The aim was to minimize deformities, scarring, and obtain good functional aesthetic outcomes based on 3 components: lining, support, and coverage.

Nasal reconstruction can be achieved with different surgical methods depending on the degree of tissue loss and the affected nasal subunits, though out of all of these methods, the forehead flap is the gold standard. The first person who described the traditional median forehead flap was Sushruta Samhita, an ayurvedic physician from ancient India 600 B.C. (1). Later, Millard designed the paramedian forehead flap, excluding the central glabellar skin with the advantage of reduced morbidity and maintained viability (2). In our case, we described a two-staged nasal reconstruction with a modified paramedian forehead flap and used a tissue expander to create a longer and wider flap for closing both donor site and nasal defect.

\section{CASE REPORT}

A 23-year-old gentleman was involved in a road traffic accident. He sustained partial nasal amputation. The laceration was closed primarily. However, the partially amputated nose was complicated with necrosis and treated conservatively. The amputated nose had fallen off and a scar had formed at the

Corresponding Author: Nurul Syazana Mohamad Shah E-mail: syazanashah@usm.my

Submitted: $16.05 .2021 \bullet$ Accepted: 05.06.2021

This work is licensed under Creative Commons Attribution-NonCommercial 4.0 International License. 
wound bed which caused nasal valve contracture and partial stenosis. He underwent nasal dilatation and was on a nasal stent.

The nasal defect was greater than $2.5 \mathrm{~cm}$ in length. There was $>50 \%$ of nasal tissue loss involving bilateral alar lobule, soft triangles, tip of nose complete loss, and the dorsum. Nasal lining and columella were not injured (Figure 1A). His forehead skin was expanded using a tissue expander. The tissue expander was filled until 300cc progressively prior to his first stage surgery. The amount of water injected was based on pain and capillary refilling time. It took 3 months to achieve adequate forehead expansion.

\section{SURGICAL TECHNIQUE}

Nasal subunits were drawn on the defect and the shape of the new nose was drawn using a sterile paper based on the size of the defect. Incision was made at the superior edge of the scar tissue along the bilateral alar rim to facilitate folding of lining component over the alar rim cartilage graft by turning down the flap to form inner lining of the nostril (Figure 1C). The paramedian forehead flap was based on the right supratrochlear artery. The artery and two branches were identified by doppler at the superior orbital rim, also the pivot point, to provide accuracy. Based on the location of the perforator, a seagull-shape forehead flap was designed. The flap was drawn with its base over the neck of the seagull and gradually widened to the distal part, resembling a seagull's body (Figure 1C,1D). The pedicle was centred on the flap to minimize post-operative flap congestion. Incision was made to remove the tissue expander (Figure 1D). The flap was raised distally. Subgaleal dissection was proceeded until the flap was raised $3 \mathrm{~cm}$ from the supraorbital rim. Subsequently, subperiosteal elevation was done to incorporate the periosteal branch of the supratrochlear artery in the pedicle.

L-shaped cartilage was harvested from the $7^{\text {th }}$ rib. It was cut into a L-strut $4(\mathrm{~L}) \times 2.5(\mathrm{H}) \mathrm{cm}$ for dorsal support and $3 \mathrm{~cm}$ thin slits cartilage for bilateral alar support. They were sutured into place with Prolene ${ }^{\circledR}$ 6-0. The flap was rotated laterally without tension and sutured to the defect refashioned contour with Nylon 6-0 (Figure 1B). We moulded the flap on the drawing on the paper and resurfaced the nose from nasal tip to the dorsum and left alar lobule. The donor site was closed primarily with the laxed skin created by the tissue expander. Additionally, adequate full-thickness skin graft (FTSG) was obtained from the excess skin on the forehead to cover the raw area over the flap's pedicle.

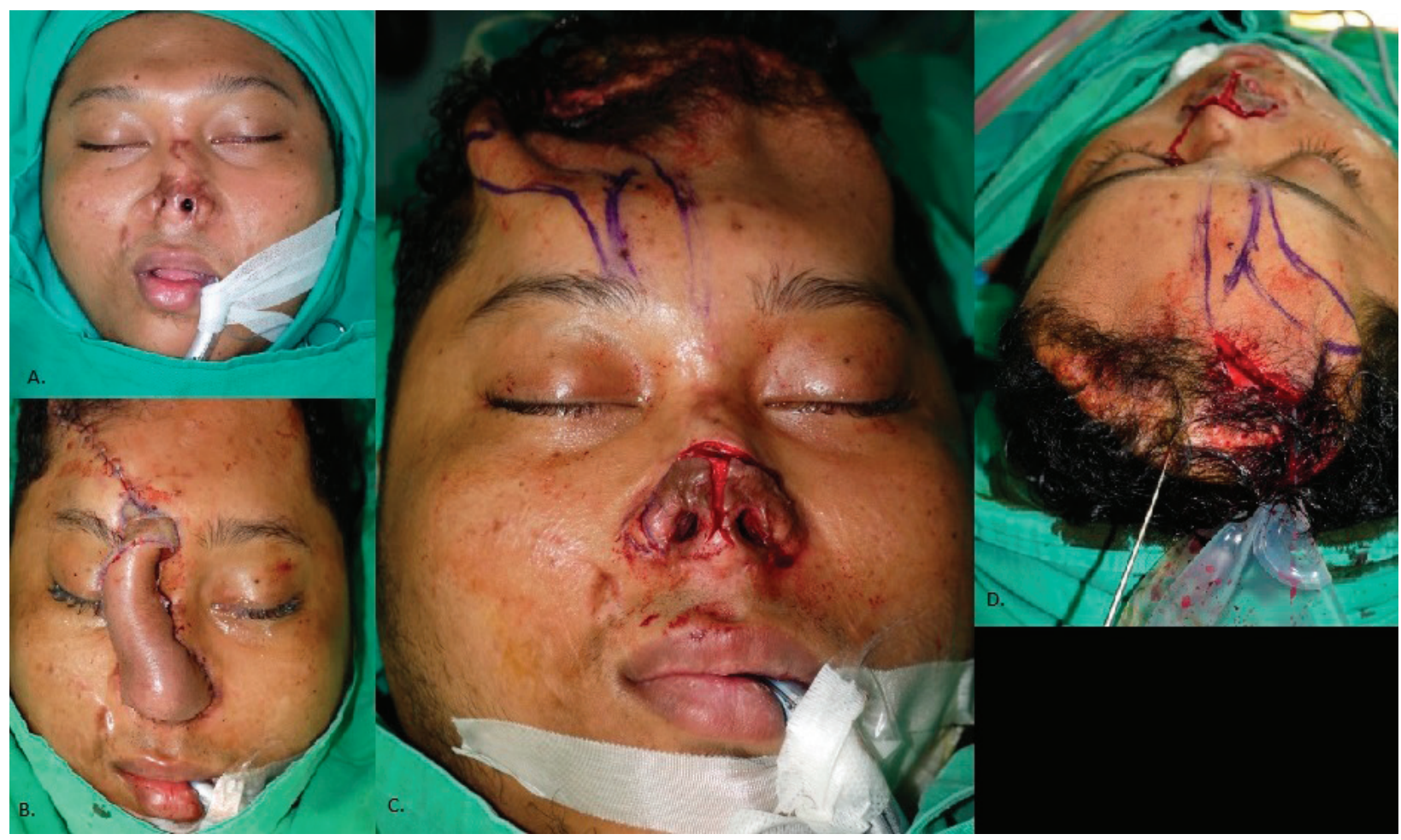

Figure 1. The process of nasal reconstruction. A. The initial nasal defect was greater than $2.5 \mathrm{~cm}$ in length. There was $>50 \%$ of nasal tissue loss involving bilateral alar lobule, soft triangles, tip of nose and dorsum complete loss. The nasal lining and columella remained intact. B. The flap was rotated laterally without tension and sutured to the defect refashioned contour. C. Incision was made at the superior edge of the scar tissue along the bilateral alar rim to facilitate folding of lining component over the alar rim cartilage graft by turning down the flap to form inner lining of the nostril. D. A seagull-shape forehead flap was designed. The flap was drawn with its base over the neck of the seagull and gradually widened to the distal part, resembling a seagull's body. Incision was made to remove the tissue expander. 


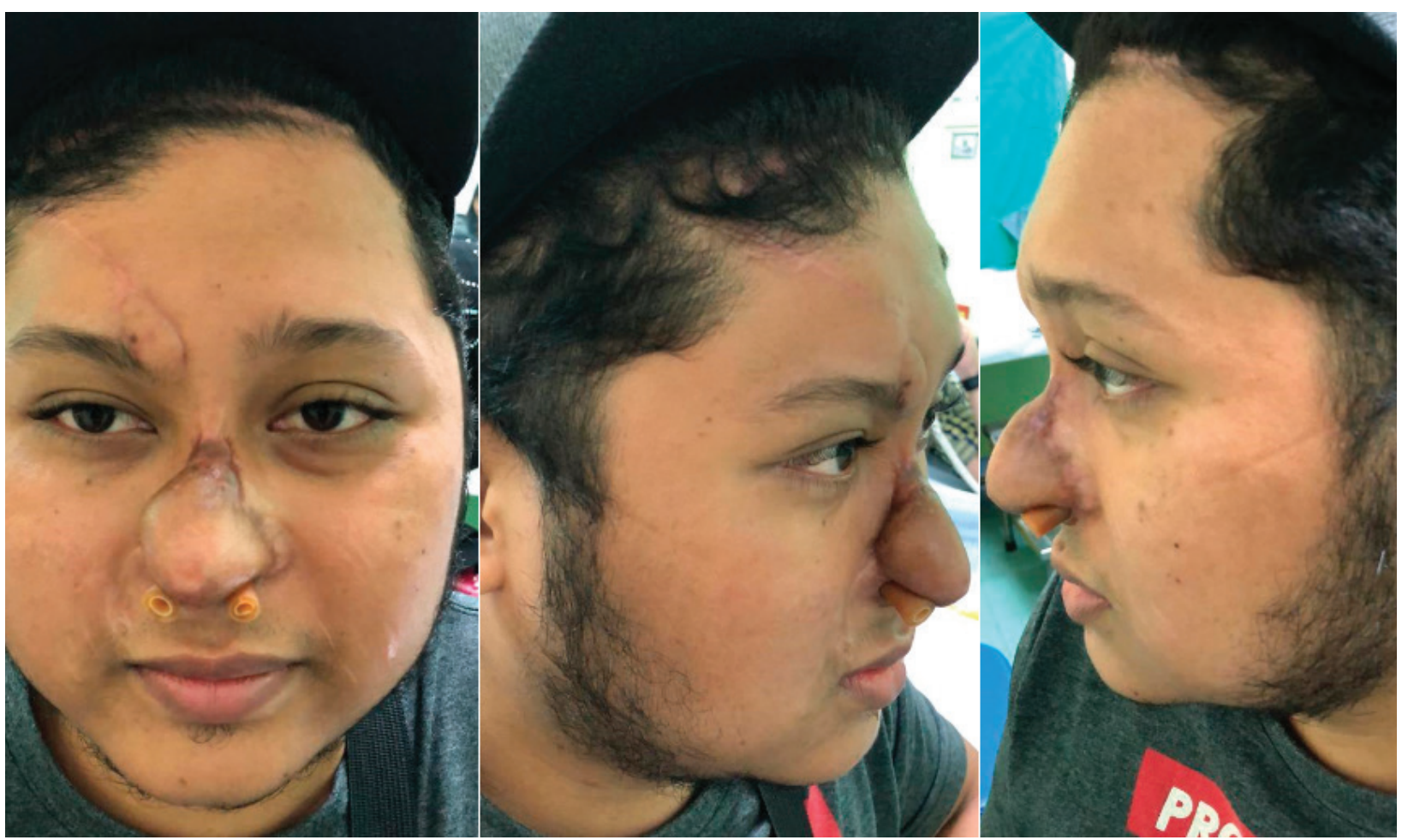

Figure 2. After 2 months, the pedicle was divided creating an inverted-V at the base. The edge of the flap was refashioned. Small portion of the superior flap edge was complicated with necrosis. There was contracture over right alar lobule. The patient underwent refashioning of flap edge and FTSG.

After two months, the pedicle was divided creating an inverted- $V$ at the base. The edge of the flap was refashioned. Small portion of the superior flap edge was complicated with necrosis, which was treated by refashioning of the flap edge and FTSG three weeks later. One month after the flap refashioning, the flap edges were healed (Figure 2). The right side of the flap was slightly bulky. There was contracture over the right alar lobule. The patient would be subjected to further surgery to reconstruct the right alar lobule. Overall, the shape of the reconstructed nose is satisfactory.

\section{DISCUSSION}

Nasal reconstruction is one of the most complex types of reconstruction surgery of the face. The nose, as a threedimensional structure at the centre of the face means that it is often the main focus of attention for the patient and also the public (3). Therefore, it is difficult to achieve patient's satisfactory on aesthetic outcome. Correa et al. stated that a defect size more than $2 \mathrm{~cm}$ wide in the horizontal plane or with exposed bone and/or cartilage were best repaired with paramedian forehead flap (3). Therefore, the gold standard paramedian forehead flap was the most suitable choice of nasal reconstruction in our case. The defect size was great and the forehead skin provided the closest texture to nasal tissue. The only pitfall the surgeon should carefully handle is the approximation of the vertical wound over the forehead caused by the secondary defect. A meticulous would closure technique is crucial to minimize wound tension that cause scarring (4).
In patients with shortened vertical forehead height, the inclusion of scalp skin in the flap should be avoided due to the difference of texture and colour of the nasal skin $(5,6)$. Our patient had a short forehead. The use of a tissue expander gave several advantages. It provided sufficient hairless length for the flap, enabled primary closure at the donor site without tension, provided extra tissue for FTSG and left an inconspicuous scar on the forehead. In addition, the expanded flap has the advantage of decreased thickness in which accurate reconstruction in two stages was permissible. Therefore, the three stage reconstruction is reserved to more complex cases that require lining repair (5). Although our nasal reconstruction with modified paramedian forehead flap had minor flap edge necrosis and contracture developed over the right alar, the major aims of the surgery were met. Further revision of the right alar region and continuing nasal dilatation is required for the long term.

\section{CONCLUSION}

Forehead flap is the best method for the repair of extensive nasal defects. Extraordinary cosmetic and near-normal functional results can be achieved. However, this method requires patience and time. Careful use of forehead tissue expander has provided great benefit for short forehead patients.

Informed Consent: Informed consent for the patient has been obtained. 
Peer-Review: Externally peer-reviewed.

Author Contributions: Conception/Design of Study- A.Z.M.S.; Data Acquisition- P.Y.; Data Analysis/Interpretation- P.Y., W.A.W.S., S.F.N.M.J.; Drafting Manuscript- P.Y.; Critical Revision of Manuscript- N.S.M.S., A.Z.M.S.; Final Approval and Accountability- N.S.M.S.

Conflict of Interest: Authors declared no conflict of interest.

Financial Disclosure: Authors declared no financial support.

\section{REFERENCES}

1. Menick FJ - Nasal Reconstruction Art and Practice. New York: Mosby/Elsevier, 2009.

2. Menick FJ. Aesthetic refinements in use of forehead for nasal reconstruction: the paramedian forehead flap. Clin Plast Surg 1990;17(4):607-22.
3. Correa BJ, Weathers WM, Wolfswinkel EM, Thornton JF. The forehead flap: the gold standard of nasal soft tissue reconstruction. Semin Plast Surg 2013;27(2):96-103.

4. Boyd CM, Baker SR, Fader DJ, Wang TS, Johnson TM. The forehead flap for nasal reconstruction. Arch Dermatol 2000;136(11):136570.

5. Pochat VD, Oliveira FC, Mata FS, Cunha MS, Alonso N, Meneses JV. Preliminary stages before nasal reconstruction using forehead flap: restoring perinasal subunits and nostril patency. Plast Aesthet Res 2015;2:34-7.

6. Weng R, Li Q, Gu B, Liu K, Shen G, Xie F. Extended forehead skin expansion and single-stage nasal subunit plasty for nasal reconstruction. Plast Reconstr Surg 2010;125:1119-28. 